\title{
Tentativa de Suicídio: O Traumático Via Ato-Dor
}

\author{
Mônica Medeiros Kother Macedo \\ Blanca Susana Guevara Werlang \\ Pontifícia Universidade Católica do Rio Grande do Sul
}

\begin{abstract}
RESUMO - A ocorrência de uma tentativa de suicídio é forte preditor para que um suicídio venha a acontecer. Neste artigo, aborda-se a tentativa de suicídio considerando-o um ato-dor decorrente da vivência de situações traumáticas. A partir da análise de cinco casos de pessoas que tentaram o suicídio, investiga-se a complexidade dessa situação por meio de uma metodologia qualitativa. Uma série de quatro entrevistas semidirigidas, elaborada para esse estudo, foi o principal instrumento para coletar os dados. Esses foram analisados por meio do método de Análise Interpretativa e com base na Teoria Psicanalítica. Foram identificadas cinco asserções que permitiram concluir a importância do dano psíquico provocado pelo trauma, assim como evidenciar a relevância do acolhimento e da escuta na situação da tentativa de suicídio.
\end{abstract}

Palavras-chave: tentativa de suicídio; ato-dor; trauma psíquico.

\section{Suicide Attempt: The Traumatic Via Pain-Act}

\begin{abstract}
The suicide attempt occurrence is a strong predictor for a suicide to happen. The present article considers a suicide attempt as a pain-act resulting from traumatic living experiences. The complex psychic situation of five individuals who attempted to commit suicide was analyzed through qualitative methodology. Four semi-constructed interviews have been carried out and they were the main instrument for data collecting. The data were analyzed through the Interpretative Analysis methodology based on Psychoanalytic Theory. Five assertions have been identified, which allowed us to understand the importance of the psychic damage caused by trauma as well as the relevance of careful listening and acceptance in the situation of suicide attempt.
\end{abstract}

Key words: suicide attempt; pain-act; psychic trauma.

Estudos sobre comportamento suicida exigem do investigador um olhar atento à singularidade dessa situação, na qual o ser humano busca uma ruptura radical para se livrar de uma dor psíquica insuportável. A tentativa de suicídio é um forte preditor de suicídio (Botega \& Werlang, 2004). Assim, compreender a dinâmica intrapsíquica e intersubjetiva, na qual se encontra o sujeito que comete esse ato, é fundamental, a fim de buscar recursos preventivos e de favorecimento à vida. Este estudo investiga a tentativa de suicídio propondona como um ato-dor circunscrito em uma dinâmica singular, em que a força de conteúdos psíquicos irrepresentáveis leva ao predomínio do traumático, daquilo que escapa ao universo representacional do sujeito.

\section{Teoria do Trauma: Ponto de Partida Teórico}

A proposição da tentativa de suicídio como uma expressão da força do traumático via ato-dor é evidenciar o caráter de violência provocado pela dor psíquica. O trauma pode ser entendido como um acontecimento da vida que se define pela sua intensidade e incapacidade do sujeito em responder-lhe de forma adequada em função de um transtorno, e/ou pelos efeitos patogênicos duradouros que provoca na organização psíquica (Laplanche \& Pontalis, 1983). A teoria do trauma

1 Endereço: Avenida Ipiranga, 6681, Porto Alegre, RS, Brasil 90619-900. E-mails: monicakm@pucrs.br e/ou bwerlang@pucrs.br encontra seu início nos textos freudianos de 1895, sendo reformulada na década de 1920. Essa teoria dá subsídios ao argumento de ser a tentativa de suicídio decorrente da força do traumático, portanto, um ato-dor. Assim, o trauma alude a uma dor irrepresentável, que tem como consequiência um ato que ocorre sem mediação e sem adiamento, daí seu caráter violento. A quantidade que irrompe no psiquismo buscará uma forma de descarga sendo que, na situação da tentativa de suicídio, o "violento" dirige-se contra a própria pessoa no ato de buscar a própria morte.

Freud (1895/1987) aborda o problema da quantidade e da dor considerando que o sistema neuronal tem como objetivo evitar todo investimento excessivo da tensão. Dor, portanto, passa a ser entendida em associação com a idéia de excesso ou de irrupção de grandes quantidades que invadem o aparelho e desafiam a capacidade de resistência das barreiras entre os neurônios. Freud (1897/1987) escreve a Fliess, em 21 de setembro de 1896, referindo-se ao abandono da teoria da sedução; assim, a idéia de traumatismo associa-se à fantasia e à intensidade dos conteúdos psíquicos. Seus textos posteriores permitem afirmar que o abandono da idéia de sedução real não significa desconsiderar a influência do traumático na etiologia das patologias.

Na virada teórica de 1920, Freud (1920/1976) apresenta o conceito de compulsão à repetição que se refere a repetições que se dão além do território do princípio do prazer, exemplificando o caráter demoníaco da pulsão. Descreve o traumatismo causado pela efração das pára-excitações devido 
ao ingresso de quantidades no psiquismo. Alerta que "outro problema surge, o de dominar as quantidades de estímulo que irromperam e de vinculá-las, no sentido psíquico, a fim de que delas se possa então desvencilhar" (p. 45). Quando ocorre o traumatismo, o aparelho psíquico não consegue mobilizar suas energias, tornando-se inoperante a capacidade de ligação das quantidades que nele ingressam. Passa a ser realizado então um trabalho de repetição, com o intuito de dar conta desse excesso de excitação.

A retomada do trauma nessa concepção econômica põe em evidência o fenômeno da repetição. Nessa direção, Pontalis (1997) afirma: "não digo o que se recompõe, mas o que insiste, é aquilo que não teve lugar, não encontrou seu lugar e que, não tendo podido se tornar, não existiu como acontecimento psíquico" (p. 28). Pode-se deduzir que o trauma corresponde a uma ausência de atribuição de sentido, sendo o ato um testemunho não somente dessa ausência, mas da presença de intensidades a qual joga o sujeito no terreno da psicopatologia.

A palavra patologia (do grego pathos) significa sofrimento; dela derivam também as palavras paixão e passividade (Berlinck, 1999). A inter-relação entre os três sentidos da palavra pathos destaca-se na situação de uma tentativa de suicídio. Esta, enquanto decorrente da força do traumático devido à incapacidade de dar figurabilidade à dor psíquica, explicita por meio de um ato-dor a relação entre sofrimento, paixão (excesso) e passividade. Conforme o autor, quando pathos acontece, "algo da ordem do excesso, da desmesura se põe em marcha sem que o eu possa se assenhorear desse acontecimento, a não ser como paciente, como ator" (p. 18). Nesse sentido, pensa-se "patologia" como um processo que envolve sempre a noção de temporalidade na medida em que alude ao ocorrido antes, remetendo à sucessão de fatos e a acontecimentos importantes na vida da pessoa.

Para Ferenczi (1932/1997), o traumático é o que não pode ser inscrito psiquicamente. A dor psíquica corresponderia ao sentimento de desagregação de si, aproximando-se da vivência de morte. Quando as tentativas de lidar com o trauma fracassam e aumenta a sensação de desagregação, medidas psíquicas drásticas precisam ser acionadas. Conforme Maia (2003), na situação de intensa dor psíquica, " $a$ saída possível para a vida parece ser a autodestruição, na medida em que põe fim à angústia avassaladora (é interessante assinalar aqui esta estranha solidariedade entre vida e morte)" (p. 149). As proposições de Ferenczi ajudam a pensar na tentativa de suicídio como um ato derivado de intensidades avassaladoras em que o sujeito paga com a renúncia à própria vida.

\section{Tentativa de Suicídio como Ato-dor}

Segundo Fischbein (1999), podem ocorrer duas formas de funcionamento psíquico frente a conflitos. Um funcionamento mais "progressivo" explicita a possibilidade simbólica de representá-los. Outro, porém, segue um rumo mais "regressivo", no qual se observam funcionamentos que tendem à descarga (passagem ao ato) frente a situações de tensão (trauma/excesso). $\mathrm{O}$ ato expressa a impossibilidade de contenção do traumático via representação simbólica. O excesso (traumático) continua impondo ao psiquismo uma demanda de trabalho para o qual aquele não encontra recursos de mediação.

Os elementos centrais do funcionamento psíquico que caracterizam algumas tentativas de suicídio apóiam-se na ausência de recursos psíquicos, a fim de dar figurabilidade e contenção à dor psíquica. Propõe-se a expressão ato-dor para nomear a tentativa de suicídio decorrente do traumático, da dor psíquica e da passividade do Eu. É um ato decorrente de dor excessiva que anula investimentos de vida ao visar, como única "saída", ao falso alívio da morte. O "tenta(dor)" de suicídio mostra, com seu ato de dar fim à própria vida, a força do traumático que o atordoa. Explicita-se assim a radicalidade de uma situação de dor psíquica. A ruptura de investimentos na vida, frente à força do traumático, encontra seu ponto máximo. A incapacidade de atribuir representação psíquica a esse excesso deixa o ato no domínio da cena psíquica.

\section{Método}

Obtida a aprovação do Comitê de Ética em Pesquisa da Pontifícia Universidade Católica do Rio Grande do Sul - PUCRS e das instituições hospitalares que atendem pacientes por tentativa de suicídio foi possível localizar os participantes deste estudo. Uma vez assinado o Termo de Consentimento Livre e Esclarecido pelo participante e contatados seus familiares para esclarecer a participação na pesquisa, iniciou-se um procedimento que consistia numa série de quatro entrevistas semidirigidas que visavam permitir ao entrevistador e ao participante a investigação, contextualização e compreensão da experiência de sua tentativa de suicídio. Nas entrevistas eram explorados a situação ocorrida, os sentimentos da pessoa e tentava-se encontrar uma forma de compreender o que ocorrera. Esse processo de entrevistas foi elaborado a partir da proposta de Schuman (1982) e Seidman (1991), sendo todas as entrevistas gravadas em áudio, conforme permissão dos participantes e, posteriormente, transcritas. Não participaram do estudo indivíduos com transtorno psicótico, retardo mental e/ou que estivessem fazendo uso de medicação com propriedades que pudessem alterar sua capacidade lógica e de raciocínio. Possibilitou-se um espaço para que o participante abordasse também temas que lhe parecessem pertinentes; buscou-se auxiliar o participante na construção e/ou fortalecimento de recursos intrapsíquicos para enfrentamento de situações conflituosas, assim como viabilizar a efetiva procura por parte do(a) mesmo(a) por um processo psicoterapêutico ou a permanência no tratamento em andamento que o ajudasse a não reincidir na tentativa de dar fim à própria vida. Dedicou-se especial cuidado e atenção ao estado emocional do participante, oferecendo-se espaços de orientação para ele e também para seus familiares. As entrevistas tiveram a duração de aproximadamente uma hora e foram realizadas na frequiência de dois encontros semanais com intervalo de dois ou três dias entre elas. Ocorreram no local da baixa hospitalar ou na clínica-escola da Faculdade de Psicologia da PUCRS.

O material obtido nas entrevistas foi interpretado por meio do método Análise Interpretativa, proposto por Frederick Erickson $(1986,1997)$, segundo o qual o trabalho com vinhetas das entrevistas realizadas com os participantes possibilita a formulação de algumas asserções a respeito do tema pes- 
Tabela 1. Dados gerais dos participantes do estudo $(n=5)$.

\begin{tabular}{cccc}
\hline Participantes* & Idade (anos) & Método da última tentativa & Número de tentativas anteriores/método \\
\hline Ana & 22 & Ingestão de medicamentos & Uma (corte pulsos) \\
Antônio & 53 & Ingestão de soda cáustica & Uma (ingestão de medicamentos) \\
Gerusa & 19 & Ingestão de morfina & Quatro (3 por ingestão de medicamentos e 1 por enforcamento) \\
Pedro & Ingestão de medicamentos & Uma (ingestão de medicamentos) \\
Teresa & 43 & Ingestão de medicamentos &
\end{tabular}

*Os nomes atribuídos aos participantes são fictícios.

quisado. A tarefa do pesquisador é descobrir diferentes estratos de universalidade e particularidades presentes em cada caso específico, explorando analiticamente o significado dos detalhes informados e das diversas camadas de significado contidas na narrativa. A apresentação das asserções, ilustradas com vinhetas e fundamentadas com comentários interpretativos com base na teoria psicanalítica, permite acompanhar o pesquisador na percepção de quais são os detalhes, entre os vários sentidos das falas, que foram considerados proeminentes e as interpretações atribuídas.

Participaram deste estudo cinco sujeitos que tentaram suicídio no período compreendido entre novembro de 2004 e setembro de 2005. Todos permaneceram, pela gravidade da ação letal, internados por um período mínimo de 24 horas. Dados gerais dos participantes são apresentados na Tabela 1.

\section{Resultados e Discussões: Apresentação das Asserções}

Após a análise das entrevistas, foram identificadas cinco asserções a respeito da tentativa de suicídio proposta como um ato-dor.

\section{Primeira asserção: na história de vida do tentador de suicídio, a vivência do traumático produz danos psíquicos}

Pedro descreve sua vida como tendo sido tranqüila até seus 12 anos. Decepcionado com as freqüentes brigas dos pais, sente sua vida mudar radicalmente:

Comecei a fumar, beber e usar drogas. (...) Eu tinha pai e mãe como heróis. (...) Eles já ficaram separados várias vezes, isso me deixava, me deixa muito machucado. Sou um cara muito sentimental, me machucou bastante. Algumas coisas que meu pai falou para minha mãe e para mim me marcou bastante.

Ana acredita ter sido "uma criança feliz" até perder o pai aos 7 anos de idade. Ficou imersa em uma situação de dor que se torna cada vez mais traumática pelo incremento do desamparo instaurado. A vida da família muda, a mãe e o irmão passam a trabalhar.
Fiquei em casa sozinha. (...) Ninguém se tocou muito no que eu estava sentindo, ninguém viu as conseqüências que aquilo podia causar.

Assim como Pedro associa a decepção com os pais ao uso de álcool e drogas, Ana associa a solidão ao início de sua compulsão para comer. O comer compulsivo é descrito por ela como uma conseqüência direta do vazio que passou a sentir após a morte do pai. Passa a ter na compulsão uma falsa alternativa de preenchimento do vazio.

Disparei a comer (...) fazia eu me sentir bem, e era uma coisa para tapar o buraco, o vazio que meu pai tinha deixado. Sei lá porque eu comia feito um animal. É como se fosse um poço, incapaz de tapar (...) atingi 115 quilos.

Pedro refere que a vida perdeu o sentido e que tinha muitas dificuldades no relacionamento com o pai antes de efetivar a primeira tentativa de suicídio aos 18 anos.

Algumas vezes ele falou que nunca seria uma família, não era uma família. Me chamou de burro, que não queria ter um filho burro. Já xingou a minha mãe algumas vezes na minha frente e isso me marcou bastante.

Antônio, aos 8 anos de idade, vive um período no qual a família passa até fome, após o pai perder todo o dinheiro com jogo e mulheres. Encontra o pai enforcado em uma árvore. Como filho mais velho, passa a ajudar a mãe no sustento dos oito irmãos menores.

Lembro-me como se fosse hoje. Meu pai estava virado com as duas mãos bem na cintura. Quando o vento bateu, ele se virou, eu corri e cheguei perto dele, os pés estavam assim uns cinqüenta, sessenta centímetros do chão, olhei para cima e vi a corda, o pescoço estava tombado para o lado. Eu me apavorei e gritei.

O suicídio do pai deixa-lhe também um caminho de identificação com a morte enquanto solução de conflitos. Anos depois se repete a história. Antônio cai no golpe de uma financeira e, não tendo possibilidade de ser reembolsado pelas perdas, tenta o suicídio. Mesmo rejeitando qualquer associação entre o ocorrido com o pai e seu ato, aos poucos ficam evidentes os pontos de repetição. Conta Antônio que o 
pai avisou a alguns amigos que iria se enforcar, convidandoos para seu velório mas, como estava alcoolizado, não foi levado a sério. Antônio refere que, no dia em que fez sua tentativa de suicídio, encontrou um amigo:

Conversando com ele que é um violeiro de mão cheia (...) disse: olha, amanhã no meu velório, tu toca a Majestade o sabiá. Se tu não tocar tu vai ver uma coisa! Ele viu que eu não estava brincando e disse: tu pára, nãofala bobagem e eu puxei a sacola mostrei a soda. Eu vou tomar, vou terminar com essa porcaria de vida. Ele quis me segurar ali, mas não conseguiu.

Na história de Gerusa, a difícil relação com o pai violento é constante fonte de dor. As lembranças trazem um colorido de intensa tristeza, medo e falta de amor.

\begin{abstract}
Meu pai era alcoolista, um homem muito violento. Não batia, mas dizia coisas que magoavam e machucavam muito. Era muito castrador, eu não podia fazer nada, ter amigos, sair, ter namorados. Ele não deixava, ficava com ciúmes Quando bebia ficava pior, mesmo sem beber não era fácil. Uma vez briguei com ele porque cheguei um pouco mais tarde em casa. Ele estava no meio da sala com a arma, veio para cima de mim. Meu irmão veio me defender, ele pegou a arma e ameaçou meu irmão. Se a gente desafiasse, ele pegava a arma. Aí eu ficava quieta.
\end{abstract}

Teresa perde seu irmão mais moço por AIDS aproximadamente três anos após perder o pai devido a um câncer no pulmão. Eles eram as duas pessoas mais próximas de Teresa. Passa a ficar horas seguidas no hospital, pois o irmão queria ser cuidado apenas por ela. Entre essas situações dramáticas, seu marido sofre um grave acidente de carro permanecendo um período significativo imobilizado, em casa, também sob os cuidados dela. Além da dor decorrente dessas situações, Teresa refere ainda muitas dificuldades com a mãe; considera que a mãe sempre gostou mais de sua irmã mais velha. Ocorrem frequientes discussões entre a mãe e seu marido sendo que a situação se agrava por morarem todos no mesmo terreno.

Quando o pai morreu, não sei o que deu na minha mãe, ficou muito agressiva, muito obsessiva (...) tudo ficou no nome dela. Ela se achou no direito de pisar nas pessoas sabe e não mede esforço, ela me magoa muito, muito. Ela pegou uma implicância com o meu marido assim demais.

Nos últimos tempos uma notícia abala Teresa: a gravidez da filha adolescente. Sente-se muito triste frente à possibilidade de repetição da sua própria história, uma vez que também casara grávida, atribuindo as dificuldades de sua vida a esse fato.

Na proposição da tentativa de suicídio como um ato-dor, a importância dada à ocorrência de uma vivência cujo valor afetivo resulta numa intensidade (excesso) que fica à mercê das condições psíquicas do sujeito de processá-la permite considerar a relação existente entre a doença e sua causalidade. No efeito do traumático na história dos participantes, levando-se em conta a singularidade de seus psiquismos, observa-se, na impossibilidade de cada um deles de processar a violência de suas experiências, a forma como impera um circuito de dor. A morte do pai de Ana, a decepção de Pedro com os pais, o golpe financeiro sofrido por Antônio, a conturbada relação de Gerusa com o pai, assim como a morte do pai, o acidente com o marido, a morte do irmão por AIDS e a gravidez da filha na história de Teresa são experienciadas como situações intoleráveis e com difícil trâmite psíquico. São excessos que se materializam nas tentativas de suicídio de cada um deles; a partir do traumático, são jogados no agir repetitivo de buscar dar fim à própria vida.

O aspecto econômico do traumático é evidenciado por Freud (1917/1976) ao relacioná-lo com esse acréscimo de quantidades as quais, pelo fato de não poderem ser processadas psiquicamente, deixam danos psíquicos que traduzem seu poder destrutivo. Na história dos entrevistados, a invasão de quantidades psíquicas vai ao longo da vida tentando encontrar, de forma precária, no ato uma via de descarga. A chegada da adolescência tanto para Pedro como para Ana, período por si só de incremento de muitas problemáticas, abre espaço para outras compulsões. Ana tenta romper todos os limites nessa época de sua vida.

Eu aos 15 anos (...) chegava em casa à hora que quisesse, comecei a beber todas, a usar maconha. Foi uma coisa libertadora, porque me sentia independente, não preciso da minha mãe, não preciso de ninguém. A bebida segue até hoje, é um inferno se não bebo (...) só tenho auto-estima bêbada.

Para Pedro, a bebida e a maconha são recursos freqüentes quando está sozinho:

Estava querendo me matar mesmo, queria me destruir. É um jeito fácil, pegar fumar, beber, é o mais fácil que tem. A maconha leva à depressão e a vários problemas. E isso me aguçou a fazer, já estava depressivo e com a droga piorou. Fiquei bem mal, comecei a fumar todo o dia, duas, três vezes por dia.

O desamparo vai se atualizando na história de cada um deles. A necessidade de beber para ter "auto-estima" mostra o quanto Ana se encontra sob o efeito desse excesso. Querer se matar mesmo é o único objetivo de Pedro, na época com 18 anos.

Segundo Maia (2003), "o transbordamento pulsional, próprio das experiências traumáticas, fará com que o sujeito busque soluções psíquicas possíveis: o traumático dói e angustia, e o sujeito terá que procurar formas para dar uma contenção a essa dor" (p. 22). No caso de Ana, percebe-se o alto custo da solução encontrada. Ao deformar seu corpo comendo compulsivamente, dá mostras do poder destrutivo da compulsão à repetição. Pedro, nas quatro tentativas de suicídio, mostra a implacável força de destruição que precisa direcionar para si mesmo. Teresa ingere, por quatro vezes, grande quantidade de medicamentos por não conseguir conviver com as situações de excesso com que se depara. Antônio destrói seu organismo ao ingerir soda cáustica, assim como Gerusa ingere morfina para extinguir a dor do vazio. Nessas tentativas, a força de impulsão ao ato está na impossibilidade de exercitar outra forma de enfrentamento da dor psíquica. Gerusa conta após uma discussão com a mãe: 
Brigamos por causa de um creme, ela dizia que a minha faculdade era cara, que não sabia como íamos ficar de pensão depois que o meu paifalecesse. Eu me senti um cheque, dinheiro, tudo que eu fazia parecia que não tinha valor nenhum. Eu me senti um nada. Saí do hospital e fui para casa. Cheguei em casa, estava precisando falar com alguém, mas sabia que ninguém ia estar lá, daí fui para a cozinha, vi os vidros de morfina que eram do pai. Daí tomei tudo.

Configura-se para Gerusa uma situação dramática pois, ao não saber quem é, fica sem capacidade de armar um recurso defensivo frente à violência da fala materna. Antecipa a não-disponibilidade do outro para escutá-la, pois esse é o modelo que conhece. Para Schneider (1988), "o traumático não depende apenas do fato de ter sido intensamente experimentado, mas de ter sido experimentado no escuro, tanto no escuro representativo quanto no escuro afetivo" (p. 26). Teresa refere não saber o que fazer com o que sente, busca um modo de aplacar a dor:

Eu estava deitada na cama, eu estava triste e sozinha já há dias (...) De madrugada, fui quietinha lá na cozinha pegar três cartelas de comprimidos, botei tudo no balcão, um monte de cartelas, aí peguei um copo de água, enchi, puxei assim para minha mão, botei tudo dentro da boca, tomei.

O traumático infiltra-se no sujeito até que sua desmesura faz com que o ato iluda com o anúncio de uma descarga e promessa de paz. O escuro representativo deixa o sujeito à mercê desse excesso. Para Gerusa, sentir-se um nada reafirma os maus-tratos de outras épocas. A capacidade representacional funciona como uma espécie de dique que protege o psiquismo de novos impactos traumáticos do real, sejam esses originários da vertente somática (pulsional) ou advindos do mundo externo (Fischbein, 1999). Após desenvolver sua compulsão por comer e beber, Ana conhece um homem pelo qual se apaixona e que lhe conta ser gay. Como não é correspondida desenvolve um quadro de anorexia, perdendo cerca de 60 quilos em sete meses. Seu corpo, na intensidade em que engorda ou emagrece, dá conta de seus ineficientes recursos psíquicos para metabolizar a dor e a angústia. Também com Gerusa as transformações do corpo parecem espelhar o excesso que está dentro dela. Devido a sua tentativa de suicídio, na qual ingere morfina, seu corpo sofre brusca transformação.

Cheguei a ter uma parada cardiorrespiratória, mas não fiquei com nenhuma seqüela. Quando eu fui para a Psiquiatria do hospital e me olhei no espelho, fiquei muito assustada comigo. Isso que já não era o jeito que eu estava antes. Dizem que eu estava enorme, parecia uma mulher de 100 e poucos quilos.

Segundo Knobloch (1998), nas relações existentes entre trauma e memória, Ferenczi (1932/1997) considera que " $a$ lembrança permanece imobilizada no corpo e é, somente aí, que ela pode ser acordada" (p. 268). O paciente encenaria sua dor diante do analista por meio de manifestações no corpo. Essa espécie de memória do corpo não se equivale aos sintomas histéricos, uma vez que não são conversões somáticas. É um modo de "pensar com o corpo", passando a ser, segundo a autora, uma forma de "expressar a multiplicidade de estados afetivos não ligados à representação" (p. 67). Em Ana, a representação plástica de um corpo esfomeado ou em Gerusa um corpo deformado por uma medicação que elimina dor, mas não a elabora, aludem à condição de desamparo e fragilidade psíquica. $\mathrm{O}$ que ingerem, excesso de comida ou excesso de medicação, denunciam o dano psíquico devido ao traumático. Encontram-se na história de vida de Ana inúmeras situações nas quais, frente a conflitos, evidenciase a singularidade das "resoluções" encontradas. Depois da anorexia, para acompanhar os hábitos de alimentação de um namorado, cria uma rotina bulímica; após as refeições, corre para o banheiro e provoca o vômito.

Com o nascimento do primeiro irmão, Gerusa, aos 2 anos e meio de idade, sem saber o que estava acontecendo, vive uma nova situação de conflito.

Rasguei todo meu vestido. A mãe conta que naquela semana eu fiquei bem sensível, queria chamar atenção (...) Eu tinha uns ataques quando ficava braba eu batia a cabeça no chão, esperneava. (...) aos poucos ia me acalmando. Mas meu pai perdeu a paciência e me deu uma surra, que era para nunca mais fazer aquilo. A mãe conta que eu nunca fiz mais, aí comecei a ter asma.

O predomínio de ausência de capacidade representacional faz com que o psiquismo fique invadido pela angústia automática, a qual é "expressão da quantidade não representável" (Fischbein, 1999, p. 265). Percebe-se, na asma de Gerusa, na bulimia de Ana, a rendição do aparelho psíquico frente às quantidades não simbolizadas.

Quando tinha 14 anos, Teresa teve seu primeiro namorado. Sofreu, então, sua primeira perda. O namorado pelo qual estava apaixonada morre afogado numa pescaria. Seu corpo ficou preso numa rede sendo encontrado somente após oito horas de buscas.

As histórias de vida dos participantes permitem identificar a presença do traumático que os deixa nesse embate entre permanecer vivos ou buscar a morte como forma de aplacar uma intensa dor. Parecem explicitar com o ato de buscar a própria morte o ato do boxe, no qual se joga a toalha frente à ausência de forças para prosseguir o combate. Sabem na sabedoria de sua dor que lutam contra o que os ataca desde dentro.

\section{Segunda asserção: o caráter compulsivo/repetitivo da tentativa de suicídio dá conta da existência de uma matriz psíquica que reproduz desesperança}

A condição representacional está abalada na situação de dor psíquica. Valls (2004) considera que o "trauma vai gerando no aparato psíquico espaços sem investimento de representação de um objeto" (p. 82) sendo que, por mais que em segunda instância tente se buscar essa representação, mesmo que ainda isso se consiga, serão investidas "representações que se prestam aos fins de repetir a sensação dolorosa e seguramente o que mais se repetirá nelas não será somente determinada cena senão o fato de que qualquer cena da vida possa terminar em dor" (p. 82). Essas cenas, segundo o autor, "buscam simplesmente repetir a dor, o trauma" (p. 
82). Pode-se pensar que o resto da dor tem como efeito a instalação de um circuito de repetição da dor, mesmo quando alcança algum tipo de representação, esta visa reproduzir o trauma. Uma dor primeira (excesso) gera repetições, que são tentativas de criar uma "representação" do irrepresentável, mas que diante da impossibilidade disso, cedem espaço ao ato como única alternativa de descarga.

Após constatar ter sido vítima de um golpe financeiro, Antônio, desesperado, toma soda cáustica para dar fim a sua vida:

Se eu perdi tudo o que tinha e não vai ser recuperado, não tem sentido. Foi isso que eu comecei a pensar, não tem sentido, não vou conseguir recuperar. Sei lá, aquilo é uma coisa gozada, é uma brutalidade contra si mesmo, mas é uma coisa sem explicação. (...) Foi uns dois minutos por aí, mais ou menos isso, um minuto e meio. Passei a me sentir mal, pegou a queimar, parecia que tinha uma fogueira dentro do meu estômago. Eu quis falar, mas não consegui. Veio uma ânsia de vômito, veio uns pedaços de carne, da barriga, do esôfago, pois eu não tinha comido nada, não tinha almoçado, não tinha tomado café. Aí aquela senhora passou (...) Chamou uma ambulância. Eu já estava vomitando sangue.

Ana tentou o suicídio por duas vezes num intervalo de dois dias.

Falei que ia tomar banho (...) destruí uma gilete (...) peguei a gilete, o cortante mesmo (...) Cortei os dois pulsos (...) a minha mãe entrou no banheiro. Aí ela gritou: o que tu está fazendo, sua louca! (...) A gente foi para a emergência do hospital. Lá o cara deu os pontos (...) eu sabia que aquela não ia ser a minha última tentativa (...) aquilo foi a minha primeira tentativa de uma série. (...) Dois dias depois eu fiz de novo, foi a mais grave. Liguei para ela (mãe) e falei: onde estão os remédios, onde está o Neosine que eu quero dormir e não consigo. E ela falou: tu vais tomar um só? E eu falei: vou e ela falou: Tu jura para a mãe? E eu, juro mãe, não vou tomar mais de um. E ela: está lá (...) dentro de uma outra caixa lá no armário. (...) vi aquele monte de remédios de tarja preta. (...) pensei é hoje que eu me mato. Aí peguei e tomei 80, tomei 80 comprimidos. Antes saí e fui na farmácia e comprei mais Nitrogin. Eu sabia que Nitrogin dava overdose. Meu erro foi que eu estava na Internet conversando com um amigo meu, e contei (...) Aí ele levou a sério e ligou urgente para a minha mãe. (...) Eu fiquei uns quatro ou cinco dias na UTI fazendo lavagem.

Para Pedro é difícil afirmar que não voltará a tentar se matar. Expressa que precisa ver como será a vida fora da clínica psiquiátrica. As quatro tentativas explicitam o caráter repetitivo de seus atos:

Na primeira vez eu estava bem mal, bem depressivo, em casa deitado, e só pensando em morrer. Saí do meu quarto, fui lá, no escritório, e estava a bolsa da minha mãe. Eu não tinha planejado tomar o remédio. Eu apenas vi a bolsa da minha mãe com os remédios e tomei. Peguei os remédios, fui para o banheiro e tomei no banheiro. (...) Vi a chance de tomar, eu queria morrer.
Conta que sua mãe não ficou muito preocupada com sua tentativa. Em uma sequiência, Pedro tenta o suicídio por mais duas vezes. A segunda ocorre 15 dias depois, e a terceira após dois meses:

Estava deitado, mal, e os remédios estavam na cozinha. Eu fui lá roubei os remédios, tomei. E aí dessa vez vomitei o remédio. (...) O médico falou que não precisava fazer lavagem nem nada. (...) Foram bem parecidas as duas primeiras vezes. (...) Fiquei uns dois meses legal (...) A minha vó me chamou pra dormir na minha tia e eu falei com o meu irmão: sabe onde estão os remédios? Ele me deu os remédios para eu tomar na minha tia. (...) lá deitei na cama e comecei a ter pensamentos, tem que tomar o remédio para morrer tem que tomar o remédio para morrer. Peguei os remédios, fui ao banheiro e tomei tudo.

Entre a terceira e a quarta tentativa por ingestão de medicamentos, Pedro tenta se enforcar. Como não obtém êxito, volta a tentar com remédios:

Na quarta vez lembro que saí com a minha mãe e na bolsa dela estavam os remédios. Perguntei para ela: mãe, que remédios que tu tem ai? Ela me deu a bolsa e eu fiquei mexendo, para ver quais os remédios que tinha. Botei a bolsa dela de novo para trás no carro. Quando chegamos em casa, vi tinha uma chave reserva do carro. (...) tirei o alarme do carro, voltei para casa. (...) Depois pulei a sacada, fui no carro e peguei os remédios. Sai correndo e tomei tudo, foi a maior dose que eu tomei assim. Eram quase 100 comprimidos. Dessa vez eu fiquei mal, (...) ela me levou direto para o pronto-socorro, para fazer lavagem.

Gerusa tenta o suicídio pela primeira vez aos 14 anos, o pai de tão alcoolizado nada percebeu. Ela convive com a violência diariamente, o que vai deixando marcas psíquicas de intensidades traumáticas ao longo de sua vida. Vive uma situação na qual o pai ameaça matar a mãe com um revólver e somente a interferência de uma vizinha que ouve o barulho, consegue acalmar o pai. Gerusa, assustada, não tem nenhuma reação.

As várias tentativas de suicídio de Pedro alertam, a quem quiser ver, para o risco de suicídio iminente. Ser deixada em casa para ser cuidada por um pai alcoolizado, ver a mãe acreditando que só a morte do pai mudaria o terror que viviam, reafirmam para Gerusa a certeza de não-solução frente à passividade instaurada. Como escreve Aulagnier (1988), o Eu é produto de sucessivas experiências de impotência nas quais foi modelado pelo outro. O Eu constrói imagens de si tendo como referência sua própria imagem e, também, a oferecida pelos outros (Hornstein, 2000). O conjunto dessas proposições e enunciados identificatórios, na medida em que possibilitam que o sujeito se reconheça de forma sucessiva, evidencia a construção do Eu num campo intersubjetivo. $\mathrm{O}$ traumático estabelece, via precariedade das relações intersubjetivas, o predomínio da dor insuportável que busca descarga em atos de desespero. Na fala de Ana, o tema da morte está sempre presente, considerando ser essa a única forma de aplacar sua dor. Os ídolos de Pedro são roqueiros que se mataram. Teresa acha a vida muito difícil, sente-se cansada de ter que ficar entre a mãe e o marido nas freqüentes 
discussões, a morte do irmão deixa-na sem esperanças e a gravidez da filha adolescente acena com a repetição de sua própria história. Teresa fez quatro tentativas de suicídio ingerindo medicamentos e referiu não sentir mais vontade de viver.

Nas contribuições de Ferenczi (1932/1997) sobre o trauma, evidencia-se o efeito de quantidades que paralisam e impedem o sujeito de viver como uma unidade psíquica. O impacto do trauma deixa o sujeito à mercê do irrepresentável, o qual mostra a força do não-nomeado ao impor um circuito de dor incessante via repetições. Frente a questionamentos sobre a possibilidade de dar novo sentido a sua vida, Ana refere sempre ter uma dificuldade para que isso aconteça. $\mathrm{O}$ sentimento predominante em Ana e nos outros participantes é de desesperança. Torna-se impossível um investimento no tempo futuro, o passado domina a cena psíquica em sua impactante atualidade devido ao predomínio do não-elaborado.

A expressão dor psíquica, segundo Maia (2003), enfatiza uma vivência de dor que se dá no limite do insuportável, associando-se à ameaça de aniquilamento do Eu. Na busca de formas para sanar a dor psíquica surgem as adições, as somatizações, a paralisia do fluxo desejante, as anorexias, as bulimias. Essas formas conciliatórias defensivas "nem sempre sedam tais estados afetivos que obedecem a uma economia de dor" (p. 69). A vontade de morrer é associada a uma falsa sensação de paz, de resolução de problemas para todos os entrevistados. Não referem outra solução para o que os faz sofrer, apenas a morte surge como recurso de extinção da dor.

Ana refere acalmar-se ao pensar em suicídio, pensa em jogar-se de lugares altos, pois agora a mãe esconde os remédios. Assim, os atos de Ana, Gerusa, Pedro, Teresa e Antônio explicitam o que descreve Fischbein (1999) sobre ser, na situação da "passagem ao ato, o momento em que podemos pesquisar a detenção e a rendição do aparelho psíquico frente ao embate da quantidade de excitação" (p. 261). Buscar a própria morte é o código para nomear a desesperança e rendição.

\section{Terceira asserção: clivagem como defesa psíquica frente ao traumático}

A clivagem está relacionada nos textos de Freud a um movimento de recusa que "abre a possibilidade de que possam coexistir no ego duas atitudes psíquicas diferentes frente à realidade: a primeira leva a realidade em consideração; a segunda, atendo-se à sobrevivência psíquica, nega-a" (Maia, 2003, p. 166). Ana nomeia-se na duplicidade, refere ter uma parte que quer fazer alguma coisa da vida, mas outra que a impede. Na história de Gerusa, o "não sentir nada” frente a mortes na família é um fato que se repete. Perde a avó paterna, um tio paterno, e também seu pai morre de câncer.

Pedro se mostra surpreso com a própria "frieza":

Tentei me enforcar em casa. (...) estava tomando um café na vó, e eu desci lá para casa sozinho. Peguei um lençol da cama da minha mãe. Amarrei na sacada da minha casa e me atirei. Eu até me espantei com a frieza com que fiz isso.

A rotina de Antônio escondia o que se passava dentro dele. Conta que se isolava usando "um disfarce", recebia pessoas em sua casa e conversava como se nada estivesse acontecendo. Mostrava-se alegre, mas algo "martelava" dentro dele, sentia que sua cabeça não estava ali. Frente à morte do namorado aos 14 anos, Teresa tem um desmaio e precisa ser hospitalizada. Fica incapacitada de acompanhar o velório e o enterro daquele que tanto amava. Ainda diz ter muito presente todo afeto que sentia por ele emocionando-se ao relatar o ocorrido nomeando uma sensação de atualidade apesar de terem se passado quase 20 anos. A clivagem aparece como única possibilidade de "defesa"; nela

coloca-se em xeque a integridade narcísica, na medida em que aquilo que é silenciado exige a redefinição do sujeito, endurecendo suas vias de afetação para com o mundo: o eu terá que vigiar este que dentro dele é vivo e morto simultaneamente (Maia, 2003, p. 155).

Ao trabalhar as proposições de Freud a respeito da cisão do eu (Ichspaltung) e da defesa denominada de desmentido (Verleugnung), Figueiredo (2003) propõe que a Verleugnung seja nomeada como desautorização. A desautorização nega a autorização para que um episódio de ruptura se inscreva no campo da experiência do sujeito e que esse sujeito se converta em autor dessa experiência. Assim, segundo o autor, o que se recusa não é apenas uma certa percepção, "mas o que vem ou viria depois dela, seja como uma percepção que a primeira torna possível, uma possibilidade de simbolização, uma conclusão lógica aparentemente necessária ou uma lembrança que a percepção pode ativar" (p. 60). Impede-se, via desautorização, "que o que se vê leve o psiquismo ao que poderia inferir daquilo que foi visto" (p. 60). As conseqüências psíquicas da desautorização se fazem notar via "permanência do episódio em uma condição de enclave psíquico" (p. 20), resultando na impossibilidade de tramitação psíquica do acontecimento traumático a fim de metabolizá-lo e metaforizá-lo. Portanto, o episódio traumático tende a persistir " $\mathrm{em}$ uma área separada, paralela e incomunicável, ele também intacto e inacessível"' (p. 20).

A cisão instalada no cerne do eu, nomeada por Ferenczi (1932/1997) como autotomia, descreve como, no intuito de sobreviver psiquicamente, o sujeito abre mão de partes do si mesmo. Na autotomia narcísica, "ocorre uma defesa contra a dor, contra o trauma, contra a catástrofe na qual se deixa algo morrer para preservar a vida" (Figueiredo, 1999, p. 135).

Ana conta que não vai a enterros, podendo-se pensar, a partir disso, o quanto suas tentativas de suicídio dão conta do que não está "enterrado" dentro dela. Ou seja, o irrepresentável que não pode ser enterrado passa a buscar vias de descarga que jogam Ana num circuito de dor e de atos repetidos. $\mathrm{O}$ recurso à clivagem se faz notar nas histórias dos participantes. Nesse sentido, Fischbein (1999) considera que "ali onde faltam as palavras aparecem as patologias do ato, e é nelas que o sujeito é atualizado por aquilo que lhe passa e não chega a controlar" (p. 266).

\section{Quarta asserção: há no tentador de suicídio um importante prejuízo na imagem do si mesmo, efeito da precariedade das relações com as figuras parentais}

Segundo Laufer (1998), a conduta e o desenvolvimento de uma pessoa não são acidentais, pois se sabe que "todo 
comportamento e desenvolvimento são reflexos da história desta pessoa, incluindo o que ocorreu entre ela e as pessoas mais importantes da sua vida, seus pais ou aqueles adultos que assumiram a responsabilidade de seu cuidado" (p. 20). Historizar o ato da tentativa de suicídio é ampliar o olhar para as formas de investimento por parte do sujeito em seus objetos. Para tal, considera-se também a qualidade dos investimentos recebidos.

A história de Ana é marcada pelo temor à solidão, assim como por um desejo de receber uma atenção absoluta por parte dos amigos. Do mesmo modo como lida com a comida, Ana investe em seus objetos. Eles precisam ser ingeridos, mastigados e, frente a algo que a desagrade, bruscamente vomitados. Como descreve Maia (2003) a respeito das adições, " a repetição do uso da droga na evitação da angústia se tornará compulsiva, e o adicto perderá o controle das situações" (p. 79).

Pedro se apaixona por uma menina quando está longe dos pais, trabalhando na praia. Decepciona-se por ela não poder ficar com ele, mas desde o início ela referira perceber que ele precisava mais de uma mãe do que de uma namorada. A paixão frustrada por ela faz com que Pedro se deprima ainda mais, tendo um episódio de quase coma alcoólica. O que mais o fascinara nela era o fato de serem muito parecidos. Gostavam de rock, vestiam-se de forma semelhante, além de ambos terem dificuldades com os pais. Ficava difícil diferenciar o que era de um e o que era do outro.

Maia (2003) descreve o narcisismo, em sua forma positiva, como sendo "aquilo que garante às individualidades $o$ sentimento de si” (p. 68). As ditas patologias do narcisismo apresentam, no terreno do investimento em si e nos objetos, sua mais crucial conflitiva, encontrando sua etiologia nas referências à dor psíquica e à ameaça de morte. Assim, "as intensidades vividas são de tal ordem que o aparato psíquico se vê inundado, precisando de recursos 'urgentes' para sanar a dor" (p. 69). Então, o fracasso das soluções encontradas faz com que o psiquismo seja regido por essa economia de dor. A paixão de Pedro por uma menina muito parecida com ele, e com a qual cria uma rápida dependência, tem uma reprise no período em que está internado na clínica psiquiátrica. Envolve-se com uma paciente usuária de drogas a qual, após a alta, terá que voltar a morar com os pais no interior do Estado. Pedro reproduz na fragilidade de seus vínculos as falhas instauradas com as figuras parentais. Teresa tem uma relação difícil com os filhos. Deprime-se ao ser contrariada e criticada:

Eu me sentia mal com aquilo. Comecei a pesar na balança, o que tenho a perder, não me querem, o que estou perdendo? Meus filhos não querem saber de mim, meu marido me recrimina toda hora, para que estou viva? Vou tomar uns remédios para ver se eles sentem falta de mim, vai ser tarde demais. Quero ver se vão dar conta de tudo sozinhos.

Antônio não conseguia buscar ajuda nas pessoas próximas a ele, queria resolver tudo sozinho, torturava-se diariamente pensando como perdera todo fruto de árduo trabalho. A fragilidade egóica está evidenciada na sensação de não poder contar com a ajuda de outro frente a uma situação de deses- pero. $\mathrm{O}$ ego atacado, via desmanche de seus projetos e ideais, não encontra recursos para amenizar a violência do golpe sofrido. Segundo Hornstein (2000), "as representações que o eu constitui de si mesmo tem como referência sua própria imagem, mas também as que lhe oferecem os outros" (p. 60). Assim, pode-se inferir a fragilidade das relações com as figuras primordiais. $\mathrm{O}$ espaço da intersubjetividade parece ter sido matizado pela falta e pela desesperança. Teresa, Pedro, Ana e Gerusa contam as dificuldades vividas com as figuras parentais.

Na história dos participantes, percebe-se o que Hornstein (2000) denomina "problemáticas narcisistas", ou seja, situações de vulnerabilidade da auto-estima. Nessas, segundo o autor, "as pessoas se tornam especialmente sensíveis aos fracassos e às desilusões" (p. 67). A modalidade de investimento narcisista de objeto está a serviço de "regular o sentimento de estima de si ou de preservar a coesão do sentimento de si" (p. 71). A fragilidade desse tipo de vínculo se explicita quando, frente à vivência de situações traumáticas, o sentimento experimentado é de extrema solidão. A noção de alteridade está comprometida quando o outro serve ao único propósito de garantir ao eu sua existência. O objeto, nesse modelo, tem a função de regulação das vivências tentando compensar o déficit intrapsíquico do eu. Quando o eu se vê atacado pelo irrepresentável há o risco de aniquilamento do si mesmo, e com isso perde-se o acesso ao outro como recurso de ajuda. Passa a não existir o que está fora do eu. Frente ao fracasso dessa tentativa de salvar algo de si mesmo, a desesperança pode levar a um desejo de morte. A precariedade e fragilidade nos investimentos libidinais denunciam a fragilidade na noção do si mesmo. Conforme assinala Hornstein (2000), "a identidade, o sentimento de si, o eu-mesmo, são noções que evocam permanência, continuidade, coesão" (p. 73).

\section{Quinta asserção: o espaço de escuta instaura condições de atribuição de sentido ao traumático rompendo o estado de clivagem psíquica}

Segundo Knobloch (1998), "a clínica do trauma é sempre uma clínica do mal-estar" (p. 31). Trabalhar o trauma via escuta analítica é a forma de abordar o irrepresentável (excesso) em um processo que busca atribuição de sentido àquilo que desassossega o sujeito. Assim, para a autora, o "lugar do traumático é, exatamente, o lugar da escuta analítica" (p. 30). Nas entrevistas realizadas pôde-se perceber como os participantes referiam ser ajudados à medida que se oferecia a eles a possibilidade de falar de suas vidas e sobre as tentativas de suicídio. Antônio fala:

Eu fui um felizardo, na hora do desespero encontrei a mão amiga, as mãos, por que foram vários, começou com o médico, acabou aqui. (...) O obstáculo que tinha me ajudou a ultrapassar, é aquela barreira do será que vai dar certo?.

As repetições abrem um importante canal de acesso à compreensão do que esse ato denuncia. No caso de Ana, Pedro, Teresa, Antônio e Gerusa percebe-se uma "repetição do idêntico", conforme refere Fischbein (1999). Esse tipo de repetição denuncia um aparelho psíquico arrasado em 
sua forma precoce pelo trauma, não tendo ocorrido uma possibilidade de elaboração. Para o autor, nessa repetição, “o curso de acontecimentos que marcam a vida parece imutável e foram fixados muito tempo antes" (p. 273).

Referindo-se ao trabalho com pacientes com impulsos suicidas, Ferenczi (1932/1997) descreveu o modo como um terapeuta pode convocar o paciente a falar sobre a situação traumática, mas agora em outro contexto. Para o autor, é favorável mostrar ao paciente que ele não está inteiramente só, destacando que, mesmo não podendo lhe oferecer tudo o que caberia em sua infância, "só o fato de que possamos vir em sua ajuda já proporciona o impulso para uma nova vida, na qual se fecha o dossiê de tudo o que se perdeu sem retorno" (p. 117). Esse, segundo o autor, será o primeiro passo no processo de ajudar o paciente a permitir "contentar-se com o que a vida oferece, apesar de tudo. Não rejeitar em bloco, mas vitalizar o que ainda pode ser utilizável" (p. 117).

O espaço terapêutico, via qualificação da escuta do condutor do processo, pode assim oferecer ao paciente a possibilidade de metabolização do traumático. Ana expressa a importância de poder se "abrir totalmente com alguém”. Demonstra a necessidade de falar e refere como se sente bem após ter sido escutada.

Depois das entrevistas, Gerusa refere que pôde passar a dormir sem a medicação. Pedro, mesmo sem poder afirmar que não reprisará suas quatro tentativas, assinala que "falar sempre ajuda”. Para Teresa, a seqüência de entrevistas foi uma possibilidade de olhar para si mesma e poder nomear a raiva que sente frente à gravidez da filha adolescente e à morte do irmão por AIDS, devido ao uso de drogas. Considera que ter tido uma "conversa franca" pôde ajudá-la muito a se olhar.

O espaço terapêutico é um aliado essencial no processo de ajuda ao "tenta(dor)" de suicídio. Mais do que nunca é preciso enfatizar a palavra dor contida no termo que o descreve. Segundo Knobloch (1998),

a análise, por intermédio da pessoa do analista, deveria dar condições ao analisando de reviver os fragmentos mortos, isto é, curá-los, para, depois, então, lembrar disto; o analista funcionaria como o agente curativo, como o que liga, cimenta os fragmentos do sujeito (p. 72).

Enfrentar a dor, unir as partes cindidas, é tirá-lo do estado de passividade e repetição criado pela violência do trauma, é trabalhar psiquicamente com o excesso. A respeito da possibilidade de elaboração das experiências traumáticas, Maia (2003) considera que

é preciso fazer surgir no setting afetos que, por sua dimensão traumática, provocam cisões patológicas para o sujeito. Entendo que o sujeito que tem sua vida psíquica em parte devassada por aspectos traumáticos age a dor, sendo incapaz de significá-la (p. 238).

Nesse sentido, ao marcar a diferença entre agir a dor e expressar a dor, a autora considera que a repetição dos afetos nesse espaço possibilita que se retire a experiência traumática da clandestinidade e do estado de dissociação.

\section{Considerações Finais}

As entrevistas realizadas com tentadores de suicídio permitiram observar a importância do efeito psíquico de vivências traumáticas em sua história de vida. Nessas histórias pessoais, o traumático resultou na impossibilidade de tramitar psiquicamente o excesso a fim de encontrar, por meio de uma atribuição de sentido, outra possibilidade de resolução dos conflitos. A fragilidade decorrente dessa situação evidencia uma seqüência de repetições que aprisionam e empobrecem a vida psíquica. A experiência de buscar a própria morte é tida como única possibilidade de enfrentar a dor. Há um importante prejuízo em relação à capacidade de representar simbolicamente o que lhe ataca o sujeito intrapsiquicamente. Nessa situação de desamparo em que se encontra torna-se difícil recorrer aos investimentos agregadores e vitalizantes de Eros. Observa-se a experimentação de um sentimento de extrema solidão e impossibilidade de buscar ajuda frente à situação dramática que vive o tentador de suicídio.

A tentativa de suicídio, como ato de buscar a própria morte, é um ato-dor do qual resulta do predomínio do irrepresentável que faz com que a dor psíquica tenda a ser evacuada via ato. $\mathrm{O}$ ato-dor é um ato decorrente da dor que o traumático provoca, é um ato de descarga de intensidades. Entender a tentativa de suicídio como um ato-dor é reafirmar a dor psíquica como força geradora de ato. Assim, na compreensão da intensidade do dano psíquico causado pelo traumático configura-se a tentativa de suicídio com um ato decorrente da vivência de intensa dor psíquica. O traumático, em sua dimensão de violência e de irrupção no campo psíquico, atordoa e paralisa qualquer tênue possibilidade de elaboração psíquica. A ausência de palavra, devido a não captura desse excesso no mundo representacional do sujeito, faz com que as reprises entrem em cena. $\mathrm{O}$ alto custo dessa dinâmica advém do aprisionamento de sua vida nesse circuito repetitivo. Muda o enredo mas a temática da dor se perpetua. As repetidas tentativas de buscar a própria morte equivocadamente podem ser apenas vistas como encenações sem sentido ou risco quando, na verdade, é a ausência de sentido do excesso que impulsiona esse ato. Encenar é pôr em cena aquilo que está como pura quantidade errante no psiquismo. Esses atos reprisados alertam para a ocorrência de uma série de atos que pode ter um final somente no derradeiro ato fatal. São repetições que contam sobre a força do que não está simbolizado, denunciam a presença-ausência do sujeito em relação a seus atos.

O ato-dor dá conta da compreensão de uma situação de tentativa de suicídio, aquela que tem o trauma como eixo central. Sabe-se da complexidade e amplitude de motivos que podem levar uma pessoa a tentar se matar. Acredita-se ser imprescindível ao profissional de saúde mental conhecer os efeitos destrutivos e mortíferos de experiências traumáticas que deixam o sujeito preso a um tempo que não passa. $\mathrm{O}$ ato, ao ser escutado, poderá ser historizado e às suas motivações poder-se-á atribuir um estatuto de passado.

Não cabe nessa proposição discutir ou problematizar a questão de legitimidade do sujeito arbitrar sobre sua própria vida. Acredita-se que, ao compreender o ato da tentativa de suicídio como um ato-dor, é impossível ao profissional de 
saúde mental desconsiderar a dramaticidade de tal situação. Defender o acesso a um espaço de escuta é acreditar no valor da vida e na capacidade de enfrentamento psíquico dos conflitos. Caberá, sim, a esse profissional mobilizar todos seus recursos técnicos e humanos para, muitas vezes, inaugurar um olhar de esperança àquele que sofre. Acredita-se que nomear a tentativa de suicídio com um ato-dor, decorrente da vivência do traumático, é trazer para o centro da cena analítica a possibilidade de historizá-lo. Como escreve Hornstein (1989),

ressignificar o passado a partir do presente permite ao paciente situar-se em uma relação distinta com sua história". Somente assim, segundo o autor, converter-se-á a história em passado, pois "essa não é passado até que se elabore, isto é, recordar para poder esquecer (p. 39).

No caso do ato-dor, ainda é necessário significá-lo, a fim de fazer com que o sujeito seja implicado nesse processo de auto-historização. $\mathrm{O}$ ato pode, assim, ceder lugar às palavras para que aos poucos o que estas simbolizem constitua um patrimônio da memória. Freud (1905/1972) afirma que "como quer que as dores sejam causadas -mesmo pela imaginação - elas próprias não são menos reais nem menos violentas por isto" (p. 302). A dinâmica que se faz presente em um ato-dor confirma essa afirmativa.

\section{Referências}

Aulagnier, P. (1988). La violencia de la interpretación: Del pictograma al enunciado. Buenos Aires: Amorrortu.

Berlinck, M. T. (1999). A dor. Em M. T. Berlick (Org.), Dor (pp. 7-22). São Paulo: Escuta.

Botega, N. \& Werlang, B. G. (2004). Avaliação e manejo do paciente. Em N. Botega \& B. G. Werlang (Orgs.), Comportamento suicida (pp. 123-140). Porto Alegre: Artmed.

Erickson, F. (1986). Qualitative methods in research on teaching. Em M. Wittrock (Org.), Handbook of research on teaching (pp. 119-161). New York: MacMillan Publishing.

Erickson, F. (1997). Métodos cualitativos de investigación sobre la enseñanza. Em M. Wittrock (Org.), La investigación de la enseñanza (pp. 195-301). Barcelona: Paidós.

Ferenczi, S. (1997). Sándor Ferenczi: Sin simpatia no hay curación. El Diario Clínico de 1932. Buenos Aires: Amorrortu. (Trabalho original publicado em 1932)

Figueiredo L. C. (1999). Palavras cruzadas entre Freud e Ferenczi. São Paulo: Escuta.

Figueiredo, L. C. (2003). Psicanálise: Elementos para a clínica contemporânea. São Paulo: Escuta.
Fischbein, J. E. (1999). Más allá de la representación: el acto. Revista de Psicoanálisis de la Asociación Psicoanalitica Argentina, 6(2), 261-280.

Freud, S. (1972). Tratamento psíquico ou mental. Em Edição standard brasileira das obras psicológicas completas de Sigmund Freud Vol. 7 (J. Salomão, Trad.). Rio de Janeiro: Imago. (Trabalho original publicado em 1905)

Freud, S. (1976). Fixação em traumas: O inconsciente. Em Edição standard brasileira das obras psicológicas completas de Sigmund Freud Vol. 16 (J. Salomão, Trad.). Rio de Janeiro: Imago. (Trabalho original publicado em 1917)

Freud, S. (1976). Além do princípio do prazer. Em Edição standard brasileira das obras psicológicas completas de Sigmund Freud Vol. 17 (J. Salomão, Trad.). Rio de Janeiro: Imago. (Trabalho original publicado em 1920)

Freud, S. (1987). Projeto para uma psicologia científica. Em Edição standard brasileira das obras psicológicas completas de Sigmund Freud Vol. 11 (J. Salomão, Trad.). Rio de Janeiro: Imago. (Trabalho original publicado em 1895)

Freud, S. (1987). Carta 69 (21 de setembro de 1897). Em Edição standard brasileira das obras psicológicas completas de Sigmund Freud Vol. 1 (J. Salomão, Trad.). Rio de Janeiro: Imago. (Trabalho original publicado em 1897)

Hornstein, L. (1989). Introdução à psicanálise. São Paulo: Escuta.

Hornstein, L. (2000). Narcisismo: Autoestima, identidad, alteridad. Buenos Aires: Paidós.

Knobloch, F. (1998). O tempo do traumático. São Paulo: EDUC.

Laplanche, J. \& Pontalis, J.-B. (1983). Vocabulário da psicanálise. São Paulo: Martins Fontes.

Laufer, M. E. (1998). El desarrolo psicologico en la adolescencia: "Señales de peligro". Em M. Laufer (Org.), El adolescente suicida (pp. 17-36). Madrid: Biblioteca Nueva.

Maia, M. S. (2003). Extremos da alma: Dor e trauma na atualidade e clínica psicanalítica. Rio de Janeiro: Garamond.

Pontalis, J.-B. (1997). Ce temps qui ne passe pas. Paris: Gallimard.

Schneider, M. (1988). L'aapproche du trauma. Le Bloc-Notes de La Psychanalysen, 8, 135-148.

Schuman, D. (1982). Policy analysis, education, and every life. Lexington: Heath.

Seidman, I. E. (1991). Interviewing as qualitative research: A guide for researchers in education and the social sciences. New York: Teachers College Press.

Valls, J. L. (2004). Metapsicologia y modernidad: El "Proyecto freudiano”. Buenos Aires: Lugar Editorial.

Recebido em 04.07.2006

Primeira decisão editorial em 31.08.2006

Aceito em 29.10.2007 